\title{
Erratum to: The absence of melanopsin alters retinal clock function and dopamine regulation by light
}

\author{
Ouria Dkhissi-Benyahya $\cdot$ Christine Coutanson $\cdot$ \\ Kenneth Knoblauch · Hasna Lahouaoui • Vincent Leviel • \\ Catherine Rey $\cdot$ Mohamed Bennis $\cdot$ Howard M. Cooper
}

Published online: 12 July 2013

(C) Springer Basel 2013

\section{Erratum to: Cell Mol Life Sci}

\section{DOI 10.1007/s00018-013-1338-9}

In the published version of the manuscript, there is a typographical error in the "Statistical analysis" paragraph on page 4 ,

"where

$M=\beta_{0}, A=\sqrt{ }\left(\beta_{1}+\beta_{22}\right)$ and $\varphi=(24 / 2 \pi) \tan ^{-1}\left(\beta_{1} / \beta_{2}\right) . "$

The correct sentence should read as

where

$M=\beta_{0}, A=\sqrt{ }\left(\beta_{1}^{2}+\beta_{2}^{2}\right)$ and $\varphi=(24 / 2 \pi) \tan ^{-1}\left(\beta_{1} / \beta_{2}\right)$.

The online version of the original article can be found under doi:10.1007/s00018-013-1338-9.

O. Dkhissi-Benyahya $(\bowtie) \cdot$ C. Coutanson $\cdot$ K. Knoblauch ·

H. Lahouaoui - V. Leviel · H. M. Cooper

Department of Chronobiology, INSERM U846, Stem Cell and Brain Research Institute, 18 Avenue du Doyen Lépine, 69500 Bron, France

e-mail: ouria.benyahya@inserm.fr

O. Dkhissi-Benyahya $\cdot$ C. Coutanson $\cdot$ K. Knoblauch .

H. Lahouaoui · V. Leviel · H. M. Cooper

Université de Lyon, Lyon 1, UMR-S 846, 69003 Lyon, France

H. Lahouaoui · M. Bennis

Laboratoire de Pharmacologie, Neurobiologie et Comportement,

Université Cadi Ayyad, Marrakech, Morocco

C. Rey

Faculté de Médecine et de Pharmacie de Lyon,

ProfileXpert-LCMT, 69373 Lyon, France 